\title{
The Journal of Neurology and Psychopathology.
}

Vol. VI.

NOVEMBER, 1925.

No. 23.

\section{Orígínal Dapers.}

DIABETES INSIPIDUS AS A SEQUEL TO EPIDEMIC ENCEPHALITIS.

\section{A STUDY OF THE WATER AND CHLORIDE BALANCE IN TWO CASES.*}

\author{
BY GEORGE W. HALL, LAURENCE H. MAYERS,
} and J. A. KERR, Chicago.

THE literature on diabetes insipidus records the work of many authors in their attempt to produce the condition experimentally. In the study of our cases we have been encouraged especially by the research work of Curtis $\dagger$, and have adhered rather closely to the methods adopted by him in his experimental observations on dogs. His conclusions were :

1. That phenolphthalein elimination was normal.

2. That high protein diet and salt added to all diets greatly increased the water exchange.

3. That the blood chloride was found to be consistently higher than normal by restricting the water and fluid and adding salt to the diet. In this way the kidney was able to concentrate both solids and chlorides.

4. That pituitary extract given subcutaneously decreased the water exchange and increased the solid and chloride concentration of the urine, and lowered the higher blood chloride.

5. He also demonstrated that the polydipsia preceded the polyuria.

TECHNIQUE.

In our work the following method was instituted: The patients were permitted to drink all the water they wished, which was carefully

* This work was carried out at St. Luke's Hospital, Chicago. Presented before the American Neurological Association at Washington, D. C., June 6, 1925.

$\dagger$ Archives of Internal Medicine, December 15, 1924.

vol. vi.-No. 23. 
measured. They were given a full-balanced diet, accurately measured and weighed, consisting of protein $141 \mathrm{gm}$., fat $142 \mathrm{gm}$., and carbohydrate $208 \mathrm{gm}$., totalling about 2,700 calories. This diet was kept the same throughout the period of the test. Since ordinary food contains water, or substances burned in the body to water, in amounts approximately equivalent to 1 c.c. for each gramme of food, the total fluid intake was calculated as the sum of the water intake, the intake of fluid food, and the weight of the food in grammes. Twenty-four-hour specimens of urine were collected, and the volume, specific gravity, and chloride content were determined daily. No attempt was made to determine the route of the remaining water loss. Since the urine contained no albumen, it could be titrated without further treatment against a standard solution of silver nitrate made up according to the method outlined in the Manual of Clinical and Laboratory Methods (Cummer), 1922. The chloride content of all the different items of food was calculated by the hospital dietician from suitable tables, and totalled for each day, and to this was added the chloride content of the table salt used to season the food, the sum being the total chloride intake. The amount of plasma chloride was determined in samples of blood taken almost every day in as nearly the same relation to food intake as possible. The method used to estimate the plasma chloride was that outlined by Austin and Van Slyke.* The patients were weighed daily.

In order to have some sort of a standard upon which to work the patients were allowed to remain on the above regime until the water intake and urine excretion remained somewhat constant. In each of the two cases about two weeks was sufficient to establish a usable normal. Burroughs and Wellcome's 'infundin' was given hypodermically to J. I. (Case I) in doses of 0.5 c.c. twice daily at first, and later 0.4 c.c. twice daily for seven days, and to W. T. (Case II) in doses of 0.5 c.c. daily for thirteen days.

No other attempts were made to vary the fluid intake or urine output because it was desired to study the effect of each factor singly. We also studied the effects of a high protein diet and of low and high salt diets.

\section{PERSONAL CASES.}

CASE I.-Our first case, which was fully reported by one of us (Hall) in the American Journal of the Medical Sciences, April, 1923, is that of a patient, J. I., who developed encephalitis in December, 1919, and was admitted to the hospital in 1921, complaining of great thirst, dryness of mouth, ravenous appetite and frequent micturition. The accompanying chart will summarize briefly his water output at that time (see Chart 1). 


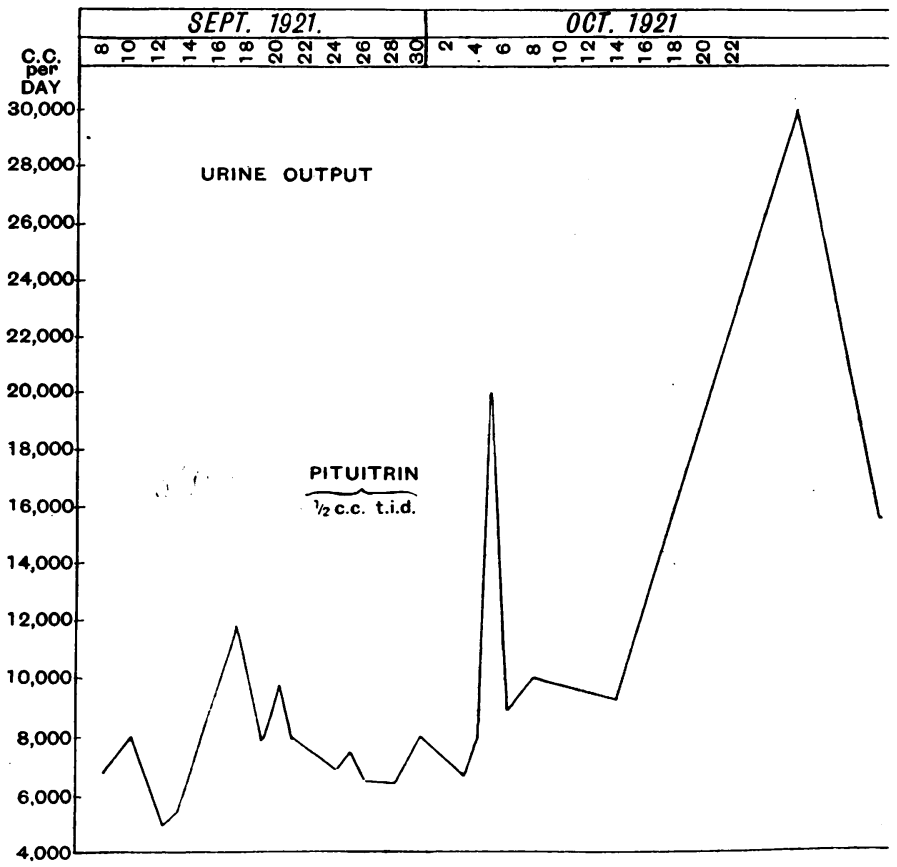

Chart 1.-Case I. J. I.

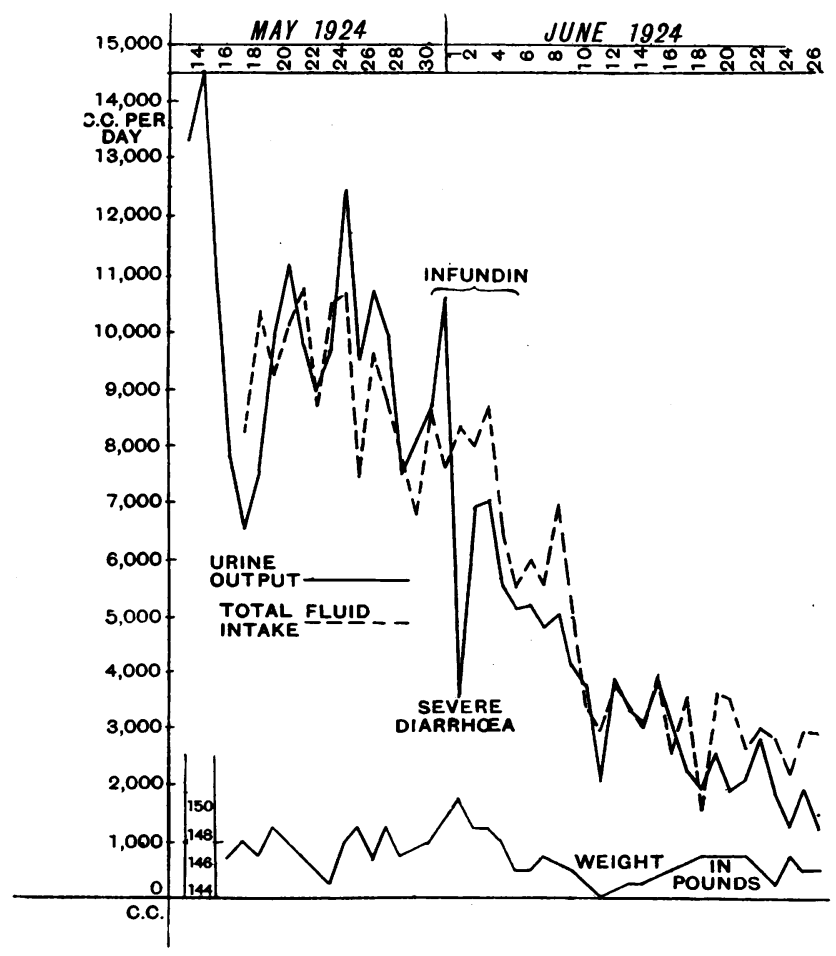

Chart 2.-Case I. J. I. 


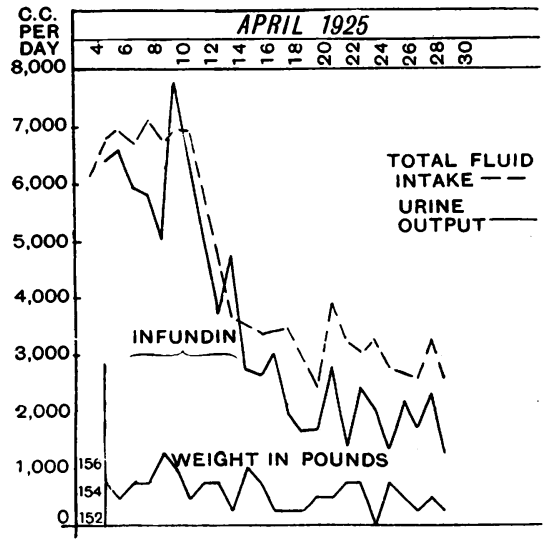

Chart 3.-Case I. J. I.

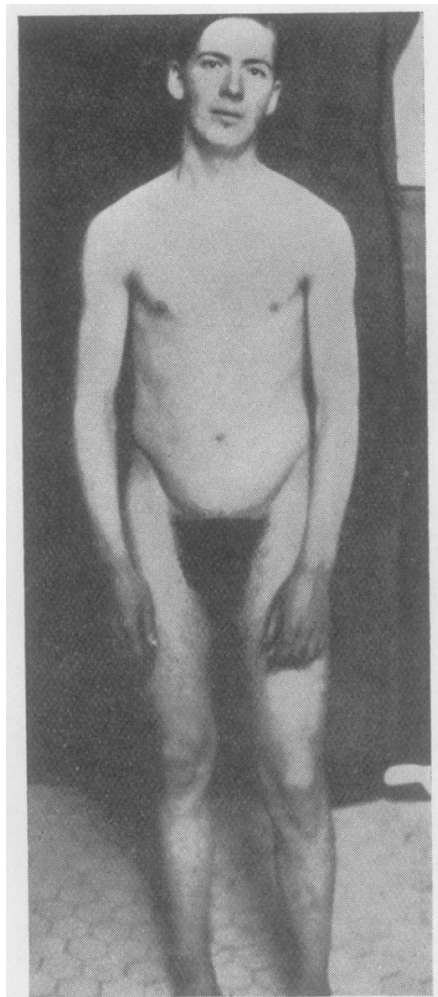

Fig. 1.-Case I. J. I., showing the Parkinsonism.

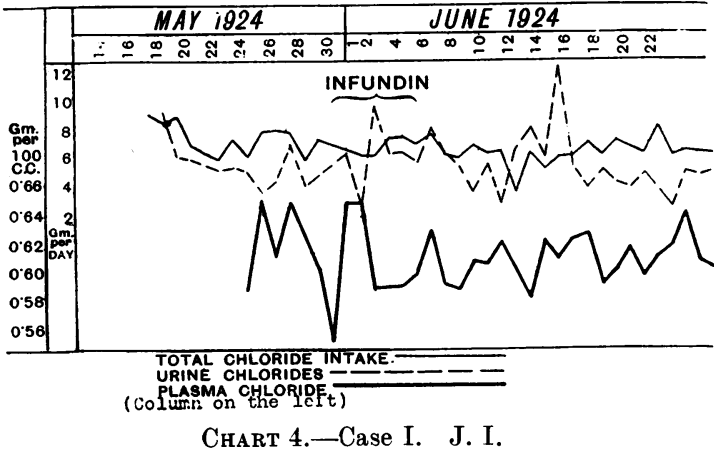

Chart 4.-Case I. J. I.

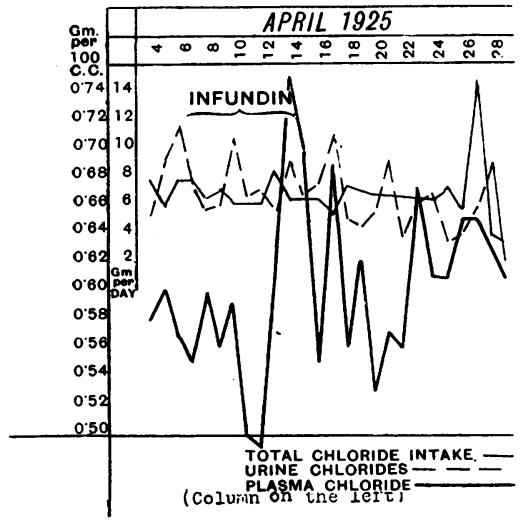

Chart 5.-Case I. J. I.

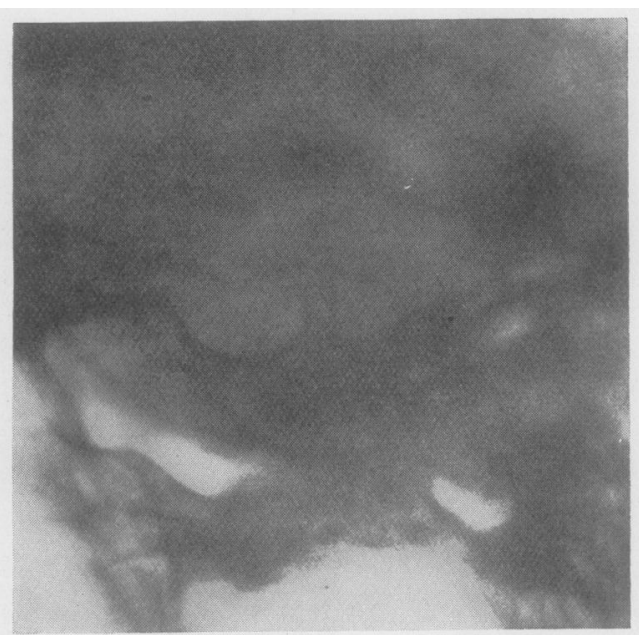

Fig. 2.-Sella of Case I. J. I. 
Our further study of his case was begun in May, 1924. As we have already stated, these studies included the record of the water intake, the water output, the chloride intake, the urine chloride, and the plasma chloride, along with the effects of the adminstration of infundin. These relations we beg to submit in the form of charts (see Charts 2, 3, 4 and 5).

CASE II.-In this case (which was diagnosed as encephalitis on admission), we submit the history as it was taken at the time of the patient's entrance to the hospital.

W. T., age nineteen years, white, schoolboy, was first admitted to St. Luke's Hospital on June 7, 1923, with the following history (taken from the hospital records).

Present Complaints.-Peculiar convulsive attacks, lethargy, and change of disposition.

Onset and Course.-Until 1920 the patient had always been quiet, studious, reserved and rather asocial. He maintains that he was very bright and had reached the third year in high school. In 1920 his parents noticed a sudden change; he became very talkative and restless. The case was diagnos $\epsilon$ d as ' brain fever' by the doctor in attendance at that time, and the illness lasted for two or three weeks. Following this he lost his former desire to read and study, becoming lazy. Otherwise, his condition was as before his illness. He had had no amnesia and no headaches.

The attacks for which the patient entered the hospital began in January, 1923. For the first two months they consisted only of 'stretching' several times a day.

On admission to the hospital, patient states that he feels the attack coming on and stands with his back against the wall. His muscles become rigid, his head is drawn to the left and backward, and the chin to the right. His clenched left fist is held close to the left side of his face, while the right is stiffly extended downward and backward. His eyes are usually closed and he holds his breath (for forty-seven seconds during one observed attack), he drools saliva from his mouth, and his jaw is drawn to the right. Following this, he bends forward, standing with his hands on his knees, relaxes, and emits a number of expiratory grunts (usually about ten). At the end of the attack he feels somewhat confused and would like to cry out, but cannot. He never has involuntary relaxation of sphincters. A single spasm usually lasts from twenty to thirty seconds, and is repeated ten to fifteen times. (Dr. Kinnier Wilson was asked to observe him during this phase of the disease.)

During the attacks the patient is usually conscious, but he has lost consciousness several times during the inspiratory phase. He fell during an attack several times early in the course of the disease, but does not fall now because he stands with his back to a wall to support himself. He does not cry out, and when he is being watched the attacks are more numerous and last longer. He does not wish to interrupt an attack because he derives a sense of satisfaction from it, somewhat akin, he says, to that derived from masturbation.

The patient states that, independently of the seizures, he derives pleasure 
from squeezing objects in his hands, from clasping hands tightly, from pressure on any part of his body, and from biting. He recognizes that this is a habit, but he cannot overcome it.

Past History.-Measles, mumps, and whooping cough in childhood. Influenza in Feburary, 1923; ' brain fever,' as mentioned, in 1920. Tonsils and adenoids removed in 1921. Two trephine operations in 1923 in a hospital in Michigan (supposedly for brain tumour). No accidents recorded. Careful inquiry reveals no abnormal conditions except as noted above. Venereal history negative.

Family History.-Father, one brother, and one sister, living and well ; mother and one sister living, but very nervous. One grandmother had tuberculosis, the other died in an insane asylum. No family history of carcinoma, kidney disease, or diabetes.

Habits.-Patient uses no drugs, alcohol, or coffee. Smokes little now, but has smoked cigarettes heavily at times. Sleeps poorly because of the attacks and accompanying nervousness. Appetite good.

Physical Examination.-The patient is a well-nourished, well-developed white male, not acutely ill. His movements are slow and deliberate. There is a papular and pustular eruption on the face, back, and chest. The facial expression is blank. The scalp hair is thin and short, and over the back of the head it is very thin, caused by rubbing the head against the wall during the seizures. The pupils react sluggishly to light, rather promptly to accommodation. Nose and ears are negative. Teeth are in good condition. Throat not inflamed. Neck and thyroid normal. Heart sounds and borders normal. No abnormal findings in the lungs. The liver is palpable below the right costal arch. There is slight tenderness in the right upper quadrant of the abdomen, but no palpable tumour masses, no rigidity or distension. Extremities are symmetrical and well developed. The knee jerks are present and equal. No Babinski sign.

Subsequent Course.-The patient was in the hospital from June 7 to June 15, 1923. He was given Fowler's solution and luminal during that time, which, while he was still in the hospital, seemed to decrease the frequency but not the severity of the attacks. The urine was normal, sp. gr. 1,020, quantity in 24 hours not measured. On July 5,1923 , he was readmitted for further observation. Attacks were then occurring about every fifteen minutes. He was discharged on July 8 , to be under the care of his family physician. On Feburary 20, 1924, the patient was again admitted, complaining of polydipsia, polyuria, abnormal appetite, coarse tremors, nervousness, and excessive gain in weight.

Interim History. - The convulsive attacks have entirely stopped, and the above symptoms have developed. He has taken luminal, about one grain a day, most of the time since he was last discharged. He has gained $44 \mathrm{lb}$. in seven months, his weight increasing from 136 to $180 \mathrm{lb}$. He had loafed around his home, not attempting to work.

Physical Examination.-Except for the obesity and the absence of the attacks, the examination shows no changes from the condition in July, 1923. Mentally, he is emotional. He acts like a spoiled child, becomes despondent, 
and cries easily. Temperature normal ; pulse 80-100; respirations 20-22. Red cells 4,220,000; leucocytes 7,650; hæmoglobin 86 per cent. Urine normal chemically and microscopically. Twenty-four-hour specimens of urine :

$$
\begin{aligned}
& \text { Feburary 22, } 1924 \text {. } \quad \text {. } 15,350 \text { c.c. } \quad \text {. } \quad \text { sp. gr. 1,005 } \\
& \text {, 23, 1924 . . } 7,730 \quad, \quad \ldots \quad, \quad 1,006 \\
& \text {, 24, } 1924 \text {. . 5,700 ,, .. } \quad, \quad 1,007
\end{aligned}
$$

$X$-ray examination, Feburary, 1924: "The sella is rather deep, and the floor is somewhat thickened. The clinoid processes are somewhat elongated. This is especially true of the posterior. The space between the anterior and posterior clinoid processes is narrowed, although there is no bridging of the processes."

On May, 1924, the patient returned to St. Luke's Hospital for a further study of the diabetes insipidus. He drinks about six quarts of water and excretes about the same amount of urine daily. He is drowsy all the day and sleeps a great part of it. He is awake at night and has felt it necessary to take luminal every night to aid his sleep.

Physical Examination.-Patient is in good health, weighing $190 \mathrm{lbs}$. There are purple striæ in the skin of the arms and legs, probably due to the rapid increase in subcutaneous fat in these regions. Muscles in good tone. Hair of the scalp, eyes, ears, nose and throat negative. Thyroid normal in size and consistency. Chest is symmetrical; no abnormalities. Heart sounds and borders normal. Abdomen negative. Genitalia within range of normal. Reflexes and sensation normal. No paralysis or paresis.

The following pictures and charts illustrate very well our study of the case. The photographs were taken in June, 1923, showing the position assumed in the course of the attack (see Figs. 3, 4, 5, 6, 7 and 8, and Charts 6 and 7).

\section{COMMENT}

Pituitary extract had a very marked effect on the water intake and output of both patients. Both said that much less water satisfied their thirst. The intake was reduced very markedly and the urine excretion was correspondingly decreased. The specific gravity of the urine rose proportionately as the volume decreased. The weight of the patients remained essentially the same throughout the period of the tests. When the administration of pituitary extract was stopped, the water intake and urine output of Case I continued to fall, while those of Case II immediately began to rise.

A study of the chloride metabolism of Case I showed the intake to be relatively constant. The excretion of chloride in the urine fluctuated rather widely. Infundin was first given in too large doses, producing a severe diarrhœa on June 1 . On that day the urine volume and chloride excretion were low and the plasma chloride high, 6.50 gm. Normal is from 5.95 to $6 \cdot 24 \mathrm{gm}$. $\mathrm{NaCl}$ per litre of plasma. The plasma chloride then dropped to about 6.02 , rising again when infundin was 


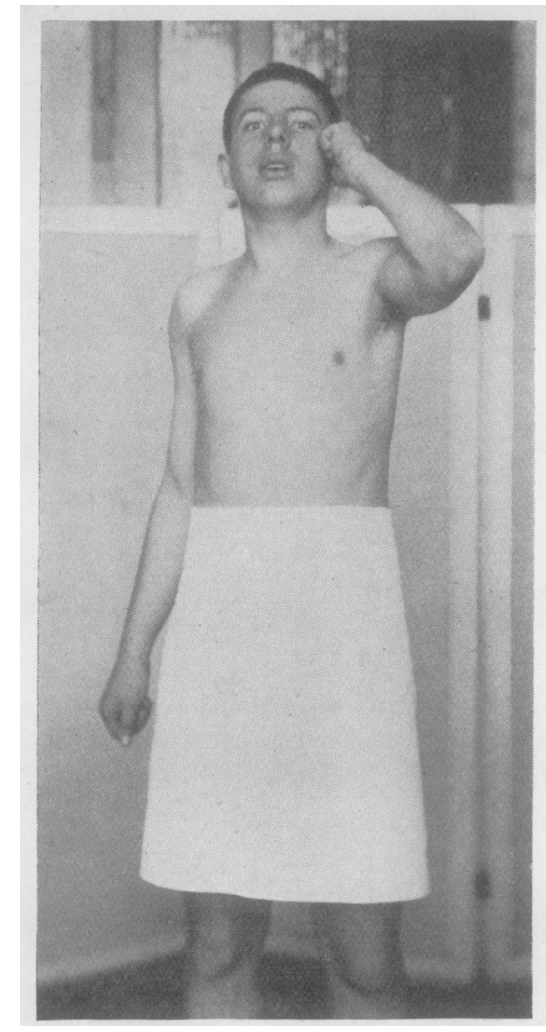

FIg. 3.-Case II. A. Showing a front view during the first phase of attack.

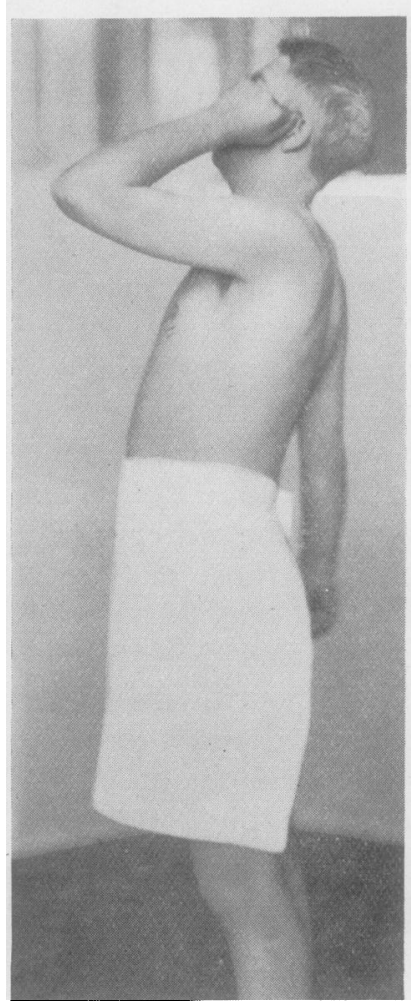

FIG. 5.-C. Showing a side view.

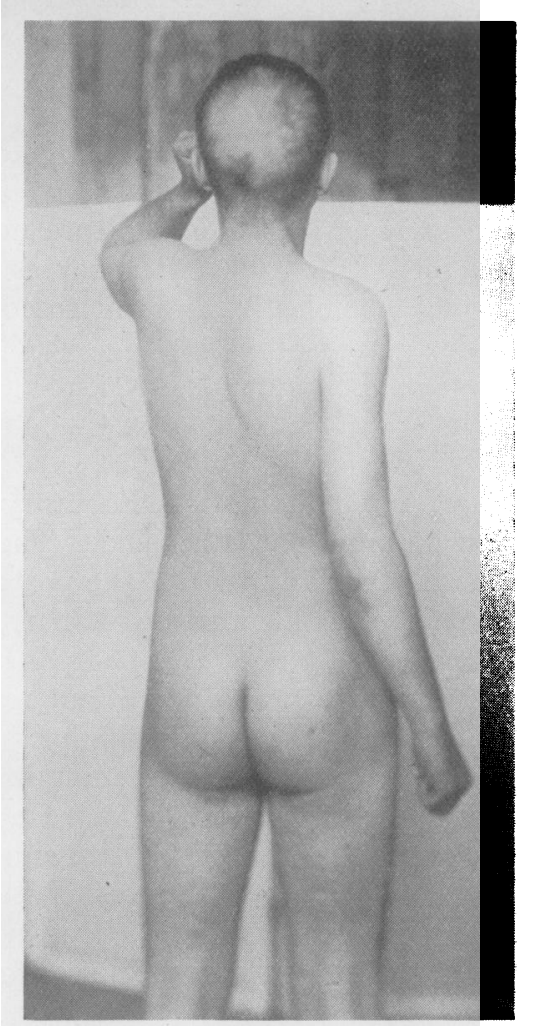

FIG. 4.-B. Showing the posterior view.

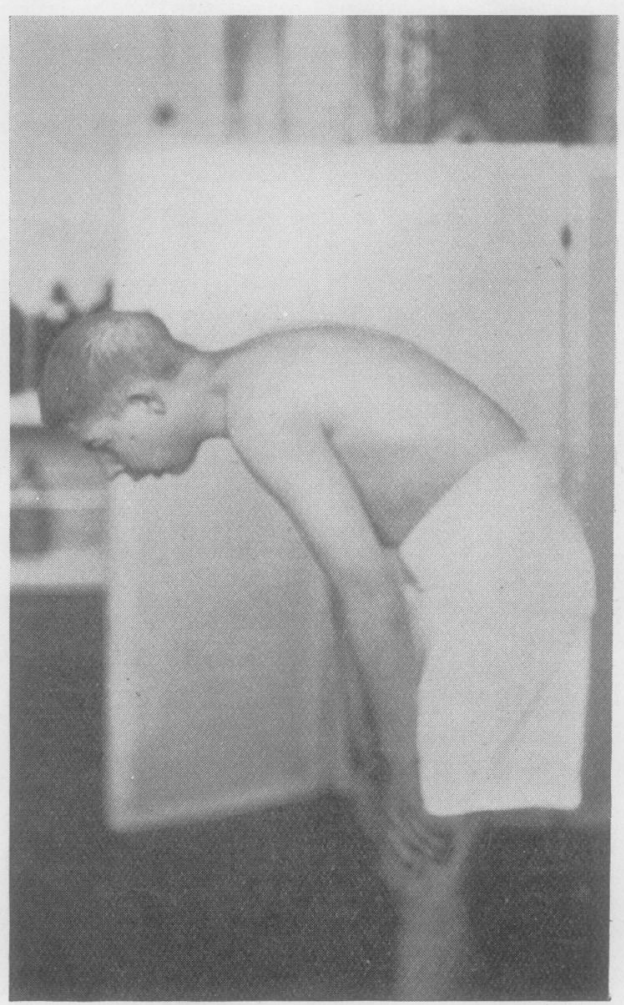

FIG. 6.-D. Showing the position of patient during the second phase of attack. 

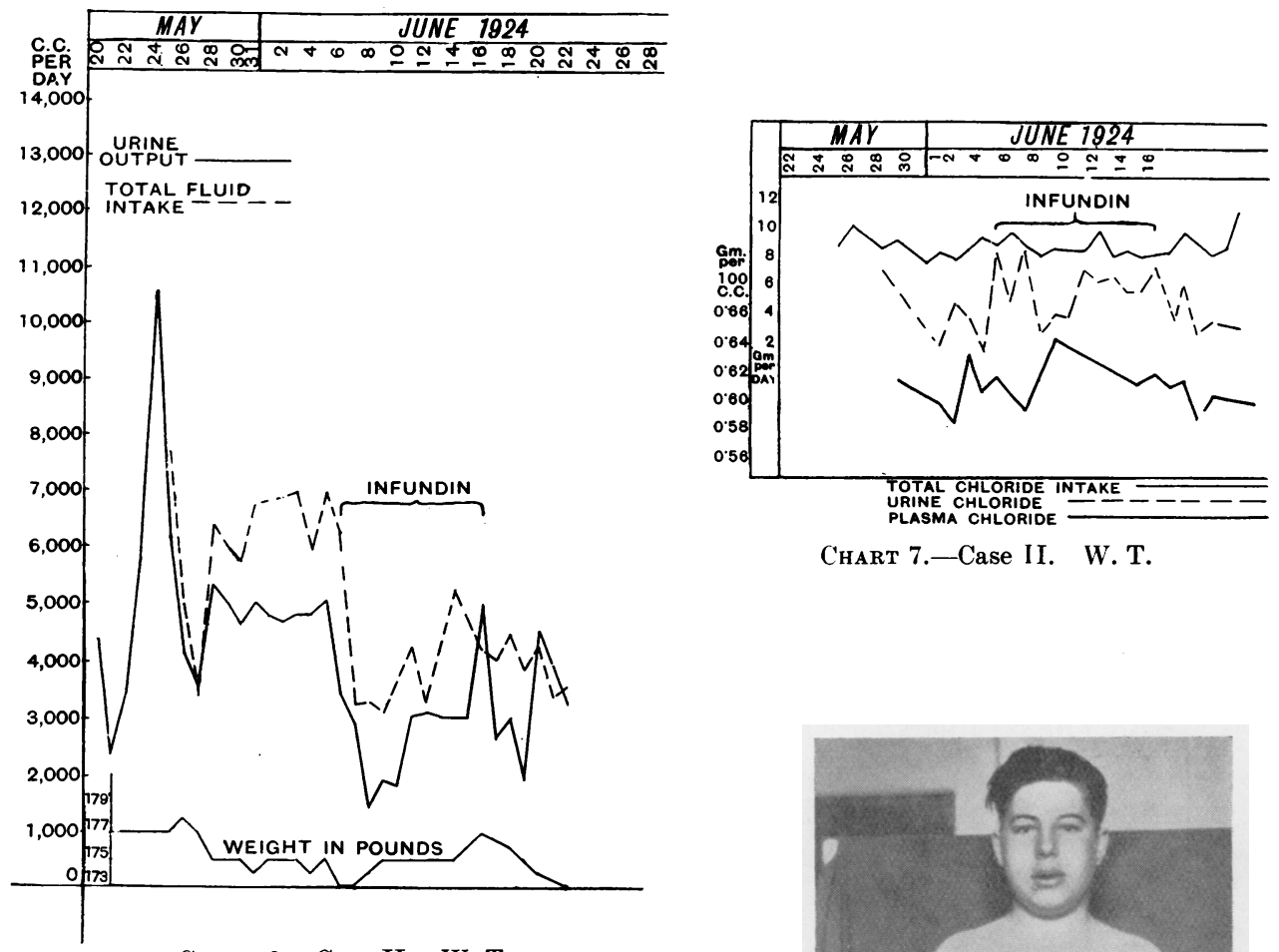

Chart 6.-Case II. W. T.
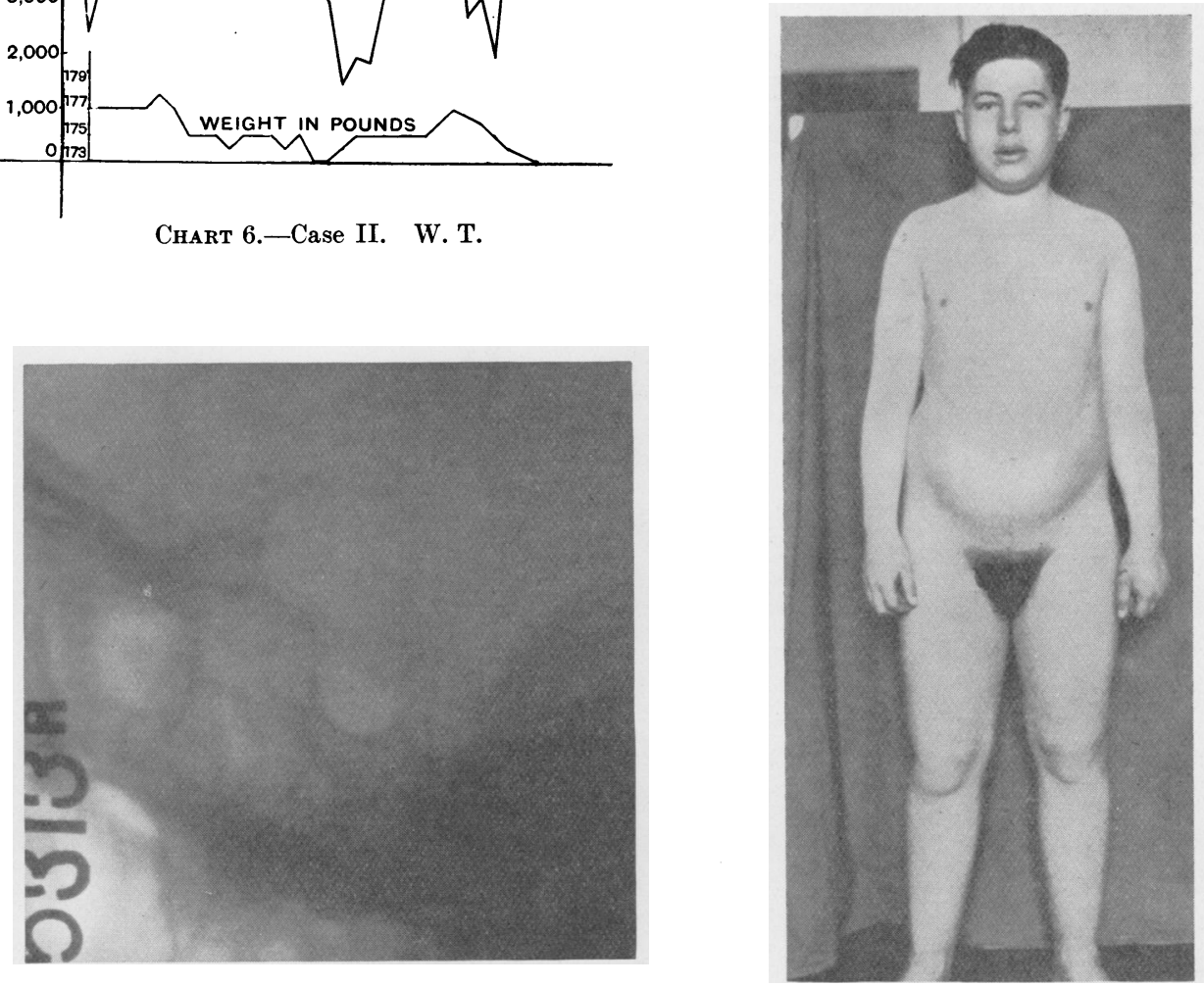

Fig. 7.-Sella of Case II. W. T.

Fig. 8.-Case II. W. T. (Taken in May, 1924). Showing the gain in weight. 
stopped, then remaining fairly constant and having a mean value thereafter of $6 \cdot 13$, the urine volume and water intake constantly falling at the last.

In Case II the chloride intake was again practically constant. When infundin was first administered there was a marked increase in the urine chloride, concurrent with a marked decrease in the urine volume and in the plasma chlorides. Following the initial increase, the urine chlorides decreased and the plasma chlorides increased, the latter then gradually diminishing.

\section{CONCLUSIONS.}

1. The only common feature which has been detected in these two cases is the decrease in water intake and in urine output when pituitary extract is administered hypodermically.

2. Polydipsia is primary.

3. Pituitary extract, when administered hypodermically, causes marked diminution of thirst in an unknown manner.

4. The kidneys are able to concentrate normally though diabetes insipidus has been constantly present for three years, and for ten months, in Cases I and II respectively.

5. Significant changes in the chloride metabolism have not been detected.

6. The phenolphthalein elimination is normal.

7. Although no medication has been given since, the polydipsia has not returned, and the output of urine in both cases has been within the normal limits.

We are indebted to the Dietetic Department of St. Luke's Hospital for their valuable assistance. 